OPEN ACCESS

Edited by:

Jalel Labidi,

University of the Basque

Country, Spain

Reviewed by:

Yanling Cheng,

University of Minnesota Twin Cities,

United States

Halil Durak,

Yüzüncü Yil University, Turkey

*Correspondence:

Weiming $Y_{i}$

yiweiming@sdut.edu.cn

Specialty section

This article was submitted to

Bioenergy and Biofuels,

a section of the journal

Frontiers in Energy Research

Received: 19 May 2019 Accepted: 07 August 2019

Published: 23 August 2019

Citation:

Wang L, Yi W, Zhang A, Li Z, Cai H and Li Y (2019) Catalytic Fast Pyrolysis of Corn Stalk for Phenols Production With Solid Catalysts.

Front. Energy Res. 7:86. doi: 10.3389/fenrg.2019.00086

\section{Catalytic Fast Pyrolysis of Corn Stalk for Phenols Production With Solid Catalysts}

\author{
Lihong Wang, Weiming Yi ${ }^{*}$, Andong Zhang, Zhihe Li, Hongzhen Cai and Yongjun Li \\ School of Agricultural Engineering and Food Science, Shandong Research Center of Engineering and Technology for Clean \\ Energy, Shandong University of Technology, Zibo, China
}

Corn stover can be converted into a high market value product via catalytic fast pyrolysis. Specifically, through thermochemical conversion, corn stover can be converted into biocrude oil with a high content of unstable phenols, most notably active phenols, which can readily react with aldehydes to form phenolic resins. Therefore, the higher the content of active phenols, the greater the economic value of biocrude oil. This is due to the potential for active phenols to serve as value-added compounds in the form of phenolic resins. Catalysts can be incorporated to improve the reaction rate and product quality during fast pyrolysis. In this study, the effects of three solid catalysts, dolomite, red mud and HZSM-5(25), on the production of active phenols were investigated. The Folin-ciocalteu (FC) method and gas chromatography-mass spectrometry (GC-MS) were utilized to quantify and classify the types of phenolic derivatives present within the bio-oil. The results showed that active phenols with a content exceeding $70 \%$ constituted the largest fraction of the phenol derivatives. The formation of active phenols, especially B-phenols, was enhanced by the incorporation of the catalysts HZSM-5, red mud and dolomite. HZSM-5 and dolomite exhibited the best catalytic effect on the production of A-phenols and B-phenols, respectively. The highest content of C-phenols (47.16\%) was achieved when red mud was utilized as a catalyst. With regard to the total content of active phenol derivatives, the catalytic effect of dolomite was better than that of HZSM-5 and red mud. The content of total phenols and active phenols increased as the reaction temperature increased from 450 to $600^{\circ} \mathrm{C}$.

Keywords: phenols, catalytic pyrolysis, bio-oil, biomass, solid catalysts

\section{INTRODUCTION}

The development and utilization of agricultural residue is closely related to the sustainability of agro-ecosystems, and it is gradually becoming an inevitable requirement for the agricultural and rural social economy $(\mathrm{Bi}, 2010)$. Fast pyrolysis is a promising technology that can convert agricultural residue into bio-oil under a temperature of $500^{\circ} \mathrm{C}$ with a fast residence time of $1 \mathrm{~s}$ (Bridgwater, 2013).

Bio-oil contains a myriad of compounds, including phenols, organic acids, ketones, aldehydes, etc. Bio-oil is regarded as a chemical material, and the phenols present within the bio-oil can be used to prepare phenolic resins after enrichment and purification (Halil, 2016; Cui et al., 2017; Halil et al., 2019). Phenolic resins have demonstrated excellent performance (adhesion strength and 
water resistance) when serving as a wood adhesive (Wen et al., 2018). Currently, the phenols used during the production of phenolic resins mainly come from the petrochemical industry. The cost of phenols accounts for more than $70 \%$ of the cost of adhesives in China, which is due to the high dependency placed on petroleum imports (Wang et al., 2016). Thus, it is of great economic benefit to find a way to replace the phenols from the petrochemical industry with phenols from bio-oil.

The generation of phenolic substances in bio-oil is dependent on the lignin components of the biomass. In order to obtain a phenol-rich bio-oil, researchers have preferred to use lignin as the raw material (or main component) to carry out catalytic pyrolysis research. The catalytic influence of solid catalysts, like soluble metal salts, metal oxides and molecular sieves, on the production of phenolic compounds has been previously investigated (Joshua et al., 2015; Shantanu et al., 2015; Lei et al., 2018; Yi et al., 2019). Wang et al. investigated the catalytic effects of three metallic chlorides $\left(\mathrm{KCl}, \mathrm{FeCl}_{3}\right.$, and $\left.\mathrm{CaCl}_{2}\right)$ on the pyrolysis of alkali lignin. The results showed that the yield of active phenols was promoted, and the catalytic strength of the catalyst cations was ranked as follows: $\mathrm{Fe}^{3+}>\mathrm{Ca}^{2+}>\mathrm{K}^{+}$(Wen-Liang et al., 2015). Three metal oxide nanoparticles $\left(\mathrm{NiO}, \mathrm{ZnO}\right.$, and $\left.\mathrm{Cu}_{2} \mathrm{O}\right)$ were loaded onto a molecular sieve and used to catalyze pyrolysis of broad-leaved lignin, and the results demonstrated that the NiOloaded catalyst exhibited the best performance to produce a high content of phenols (Nevenka et al., 2013). Lu et al. previously developed $\mathrm{Ph}$ and $\mathrm{Ce}$ metal catalysts with $\mathrm{TiO}_{2}$ and $\mathrm{ZrO}_{2} / \mathrm{TiO}_{2}$ supports, respectively. The results showed that the unmodified and modified $\mathrm{TiO}_{2}$ catalyst was favorable for the conversion of lignin into phenolic derivative monomer compounds, which increased by $11.6 \%$ compared with the blank group ( $\mathrm{Lu}$ et al., 2010). Günay (2015) studied the catalytic effects of $\mathrm{KOH}, \mathrm{ZnCl}_{2}$ and $\mathrm{ZnO}$ on the pyrolysis of pine wood chips. The results showed that the addition of $\mathrm{ZnCl}_{2}$ increased the content of aldehydes in biological oil, whereas $\mathrm{ZnO}$ had a negative effect on the formation of aromatic hydrocarbons. In addition, the content of phenols was found to increase with the incorporation of $\mathrm{KOH}$. However, rapid catalyst deactivation through fouling, coking or destruction of the support matrix can occur, resulting in either a short catalyst lifetime or at least the need to continuously regenerate the catalyst. Both scenarios necessitate major capital and/or operating costs. It can thus be argued that the development of an effective and robust catalyst system adapted to the specific requirements of the bio-oil constitutes one of the main hurdles for its widespread development in an economically viable manner (Sanna and Andrésen, 2012). Thus, looking for an inexpensive and potentially sacrificial catalyst system could be the answer to this challenge (Elham et al., 2014).

Some solid catalysts including dolomite, red mud and HZSM5 have been widely used in industrial catalytic production because these catalysts are easy to acquire and are cost effective. The main components of calcined dolomite are $\mathrm{CaO}$ and $\mathrm{MgO}$, which can improve the quality of bio-oil and retain a high bio-oil yield (Zhou et al., 2005; Li and Wu, 2009; Putun, 2010; Shiyu et al., 2016). As shown in previous research, mesoporous catalysts have good fracture effects on biomass, and the addition of $\mathrm{CaO}$ can lead to the cracking of large-molecule oxygenates that are generated from pyrolysis (Yunwu et al., 2019). Red mud is a waste residue produced during the process of refining alumina from aluminum ore and contains various metal oxides (Karimi et al., 2010; Justin et al., 2019). Microporous HZSM-5 catalysts have been recognized to be the most efficient catalyst for the preparation of aromatics by catalytic pyrolysis because of their special three-dimensional structure and their deoxidization and isomerization effect (Yunwu et al., 2019). In recent years, HZSM5 has gained increasing attention as a catalyst for the pyrolysis of lignocellulosic biomass (Hyung-Su et al., 2014; Yu et al., 2014; Huamei et al., 2018). The excellent catalytic properties of dolomite, red mud and HZSM-5 on fast pyrolysis of biomass have been previously demonstrated by multiple studies. $\mathrm{Xu}$ investigated the effect of calcined dolomite on the quality of biooil from corn stalk, and this study found that the acidity of bio-oil was reduced and the content of phenols increased (Xu, 2016). Wang et al. used red mud that had removed $\mathrm{Na}^{+}$and $\mathrm{Ca}^{2+}$ during the pyrolysis of alkali lignin. Although the bio-oil yield reduced, the alkylphenol and hydrocarbon content increased significantly (Shaoqing et al., 2018). Shen et al. (2015) found that HZSM-5(25) promoted the pyrolysis of lignin to produce aromatic monomers when the reaction temperature was lower than $650^{\circ} \mathrm{C}$.

Phenolic hydroxyl is an electron donor group which increases the density of the electron cloud on the benzene ring, especially when the additional hydroxyl functional group is in the ortho position. Therefore, the electrophilic substitution reaction is prone to occur in the benzene ring, and the substituents are mainly in the ortho and para positions of the phenolic $-\mathrm{OH}$ functional group. During condensation reactions with aldehydes to produce phenolic resins, only the ortho and para positions of the phenolic hydroxyl group demonstrated reactivity. The reactivity reduced when the ortho and para positions contained functional groups. The phenolic hydroxyl group has been reported to lose reactivity whether the three active sites were substituted or not (Zhao et al., 2011). Therefore, the presence of active phenols in bio-oil can increase its chemical and commercial value. Active phenols in bio-oil have included phenol, methyl (oxy) phenol, dimethyl (oxy) phenol, resorcinol, etc. (Ioannidou et al., 2009; Charles et al., 2010; Jewel and Sergio, 2012; Peng et al., 2018). Researchers have previously paid much attention to the representative phenolic compounds and the normalization analysis of phenols detected by GC-MS. However, how the removal of ortho and para functional groups of phenolic hydroxyl (such as methyl and methoxyl) is affected by catalysts has not yet been investigated.

Corn stalk is an abundant agricultural waste in China. The high value utilization of corn stalk has the potential to alleviate problems associated with energy security and environmental pollution (Zhao et al., 2011). Hence, in this study, corn stalk was chosen as a feedstock along with three sacrificial catalysts (dolomite, red mud, and HZSM-5) in order to (1) investigate the catalytic effects of HZSM-5, dolomite and red mud on the production of active phenols; (2) reveal the role of temperature on the pyrolysis of corn stalk and the content of active phenols; (3) provide guidance regarding the formation of enriched highactivity phenols in bio-oil. 


\section{EXPERIMENTAL SECTION}

\section{Feedstock}

Corn stalk was collected in Zibo, China. The feedstock was firstly air dried and crushed to a size of $200 \mu \mathrm{m}$. The material powder was then dried at $150 \pm 5^{\circ} \mathrm{C}$ in a blast drying oven. The dried material was sealed and stored in a drying vessel prior to further analysis and experiments. The proximate and ultimate analysis results of the feedstock are listed in Table $\mathbf{1 .}$

\section{Catalyst Preparation}

Zeolite and HZSM-5(25) were purchased from Tianjin Nankai chemical reagent company (China). Dolomite with a purity of $85 \%$ and $\mathrm{SiO}_{2}$ content of $11.5 \%$ was purchased from Long Xiang Co., Ltd. in Zibo, China. Dolomite was a complex carbonate salt and was primarily composed of $\mathrm{CaMg}\left(\mathrm{CO}_{3}\right)_{2}$. Red mud was the waste slag produced during the alumina sintering process, and it was obtained from Shandong Aluminum Corporation (China). Red mud had a complex chemical composition and contained many hydrated and carbonated minerals. In order to remove the impurities, the zeolite catalyst was calcined at $550^{\circ} \mathrm{C}$ for $3 \mathrm{~h}$ in a muffle furnace. Dolomite and red mud were crushed to a size of $120 \mu \mathrm{m}$ and then heated to a temperature of $800^{\circ} \mathrm{C}$ for $4 \mathrm{~h}$. The three catalysts were preserved in wellsealed containers prior to utilization. After exposure to high temperatures, dolomite consisted of a $\mathrm{CaO}-\mathrm{MgO}$ complex ( $\mathrm{Li}$ and $\mathrm{Wu}, 2009)$.

\section{Catalyst Tests}

The compositions of the three prepared catalysts were analyzed by X-ray Fluorescence (XRF) (RIGAKU, ZSX100e). The porous structures of the catalysts were determined by an automatic surface area and porosity analyzer (Micromeritics Instrument Corporation, Tristar II 3020).

The catalytic experiments were conducted on a fixed bed tube furnace. An illustration of the experimental setup is shown in Figure 1. The pyrolysis reaction tube was a quartz tube with an inner diameter of $55 \mathrm{~mm}$ and a length of $680 \mathrm{~mm}$. $\mathrm{N}_{2}$ was used as the carrier gas and was purged into one side of the reaction tube, and the other side was connected to the condensing system. In each study, corn stalk and catalyst were mixed at a mass ratio of 2:1 and then loaded into a silica boat. The feedstock was then pushed into the quartz reactor for in situ catalytic pyrolysis. The reaction temperatures utilized for catalytic pyrolysis were 450, 500,550 , and $600^{\circ} \mathrm{C}$. In order to collect all of the bio-oil after the reaction, the bio-oil was condensed in a water bath at a temperature of $-10^{\circ} \mathrm{C}$.

\section{Product Analysis}

The organic composition of the bio-oil was analyzed by a gas chromatography-mass spectrometer with a capillary column of DB-1701 (GC-MS) (Agilent 6890/5973, USA). Helium gas with a purity of $99.9999 \%$ was used as the carrier gas. The automatic injection volume was $0.2 \mu \mathrm{L}$, and the split ratio of the sample injection was 60:1. The column temperature increased from 40 to $240^{\circ} \mathrm{C}$ with a heating rate of $5^{\circ} \mathrm{C} / \mathrm{min}$, and the final temperature was held for $5 \mathrm{~min}$. The temperature of the injector, GC-MS connector, ion source and MS quadrupole were 280, 250, 230, and $150^{\circ} \mathrm{C}$, respectively. The identification of chemical compounds was performed by comparing the spectra of all chromatogram peaks with the database of spectra in the NIST Database.

The total phenolic content was determined based on the Folin-Ciocalteu (FC) method. Tungsten and molybdenum with a high valence in the forint reagent can be reduced by phenolic $-\mathrm{OH}$ in the bio-oil, thereby forming molybdenum blue and tungsten blue, respectively. Thus, the total phenolic content can be determined by the color of the reaction mixture. The color of the reaction mixture becomes darker as the total phenolic content increases $(\mathrm{Xu}, 2016)$. Bio-oil was added into a mixture of $\mathrm{FC}$ and 20 wt.\% $\mathrm{Na}_{2} \mathrm{CO}_{3}$ after being diluted to different concentrations. The total phenolic content was determined based on the absorbance of the mixture and was subsequently compared with a standard curve. Before analysis, standard solutions were prepared, and standard curves were established (Figure 2). The resulting regression equation is shown in the following equation:

$$
\begin{aligned}
Y & =1.4657 x-1.6133\left(R_{2}=0.9933\right) \\
C & =\frac{Y}{D}
\end{aligned}
$$

Where $\mathrm{Y}$ and $\mathrm{X}$ are the total phenolic concentration $(\mathrm{mg} / \mathrm{L})$ and absorbance of bio-oil, respectively. The density of bio-oil (mg/L) and total phenolic content (\%) are $\mathrm{C}$ and $\mathrm{D}$, respectively.

\section{RESULTS AND DISCUSSION \\ Characterization of Catalysts}

The composition of the three catalysts is listed in Table 2. HZSM-5 primarily consisted of crystalline aluminosilicates, which mainly took the form of $\mathrm{Al}_{2} \mathrm{O}_{3}$ and $\mathrm{SiO}_{2}$. The main chemical components of dolomite were $\mathrm{CaO}, \mathrm{MgO}$, and $\mathrm{SiO}_{2}$. Red mud had a complex chemical composition and contained hydrated minerals and carbonated minerals. The main chemical components were $\mathrm{Fe}_{2} \mathrm{O}_{3}, \mathrm{Al}_{2} \mathrm{O}_{3}, \mathrm{SiO}_{2}, \mathrm{Na}_{2} \mathrm{O}$, and $\mathrm{CaO}$.

\begin{tabular}{|c|c|c|c|c|c|c|c|}
\hline Moisture $^{a}$ & $A s h^{b}$ & Volatiles $^{\text {b }}$ & Fixed carbon ${ }^{b, c}$ & Nitrogen $^{\mathbf{b}}$ & Carbon $^{b}$ & Hydrogen $^{b}$ & Oxygen $^{b}$ \\
\hline 8.41 & 9.46 & 67.58 & 14.54 & 1.30 & 39.01 & 5.03 & 45.15 \\
\hline
\end{tabular}

TABLE 1 | Proximate and ultimate analysis results of corn stalk (wt. \%).

a air basis.

${ }^{b}$ dry basis.

${ }^{c}$ by difference: Fixed carbon wt.\% $=100$ - Volatiles (wt.\%) - Ash (wt.\%). 


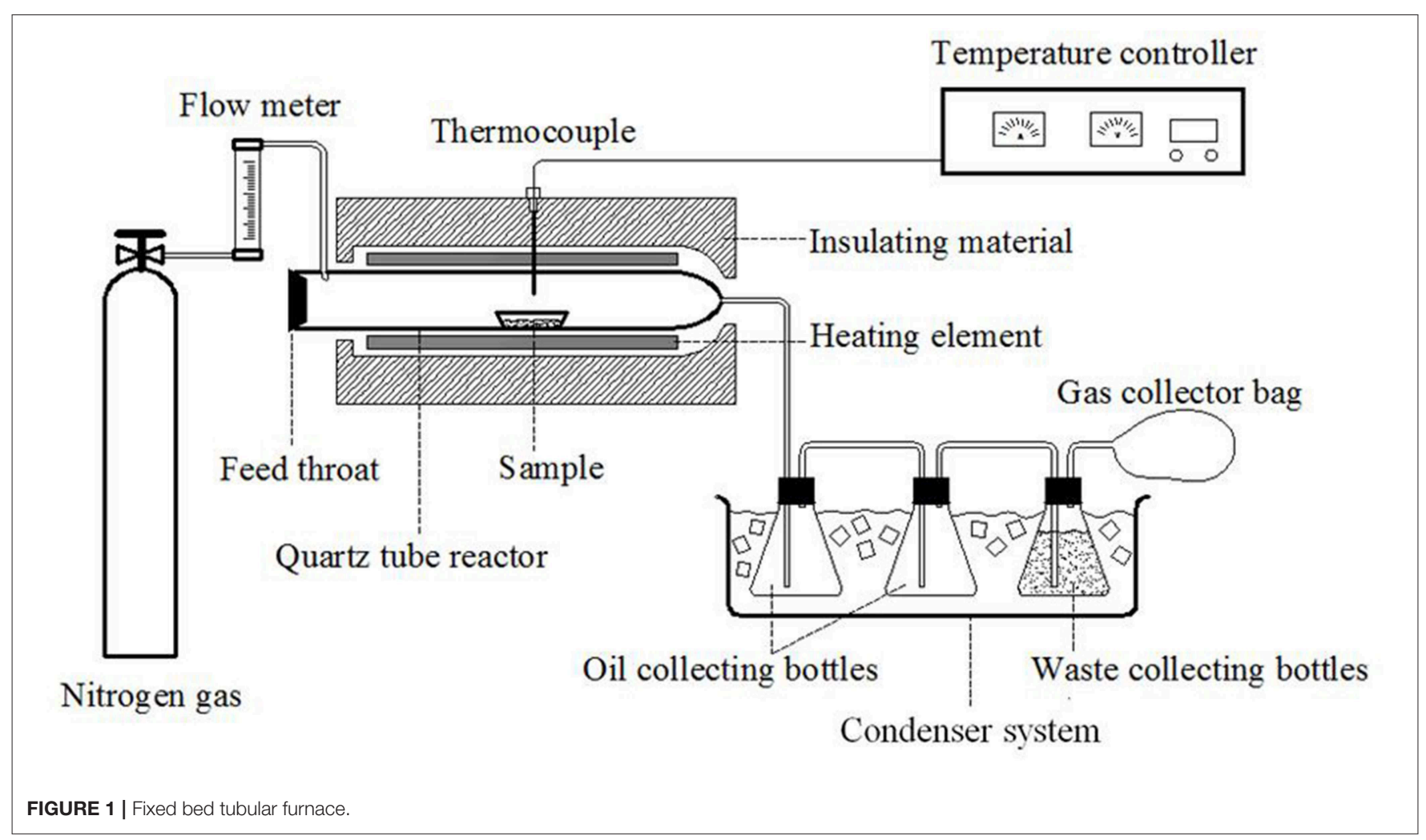

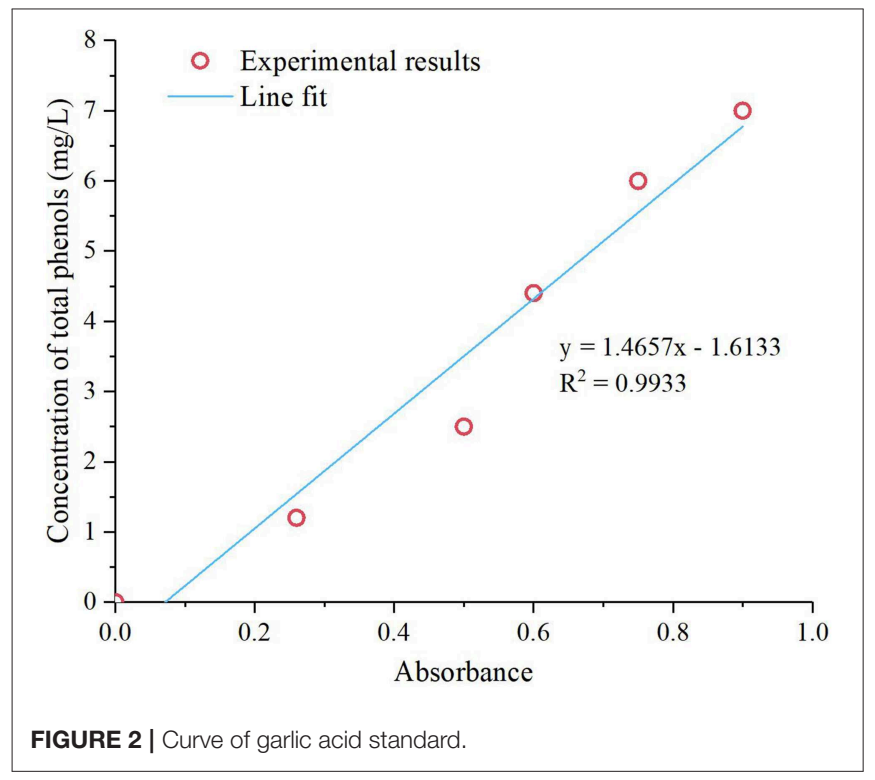

The analysis of the catalyst specific surface area and pore structure is presented in Table 3. For the raw catalysts, mesoporous catalysts (dolomite and red mud) had larger pore sizes than HZSM-5, which was favorable for catalytic cracking of the macromolecular materials. HZSM-5 had a smaller pore size $(2.24 \mathrm{~nm})$, larger specific surface area $\left(364.28 \mathrm{~m}^{2} / \mathrm{g}\right)$ and larger pore volume $\left(0.2541 \mathrm{~cm}^{3} / \mathrm{g}\right)$ than the other two catalysts. The contact area of HZSM-5 with vapor molecules was larger than the
TABLE 2 | XRF analysis of the catalyst samples.

\begin{tabular}{llcc}
\hline Composition & HZSM-5 & Dolomite & Red mud \\
\hline $\mathrm{Fe}_{2} \mathrm{O}_{3}$ & UDL & 0.46 & 29.90 \\
$\mathrm{Al}_{2} \mathrm{O}_{3}$ & 5.30 & 0.04 & 21.90 \\
$\mathrm{SiO}_{2}$ & 91.20 & 11.50 & 18.60 \\
$\mathrm{CaO}$ & $\mathrm{UDL}$ & 45.50 & 11.80 \\
$\mathrm{Na}_{2} \mathrm{O}$ & $\mathrm{UDL}$ & $\mathrm{UDL}$ & 12.90 \\
$\mathrm{TiO}_{2}$ & $\mathrm{UDL}$ & $\mathrm{UDL}$ & 2.46 \\
$\mathrm{~K}_{2} \mathrm{O}$ & UDL & UDL & 0.45 \\
$\mathrm{MgO}$ & UDL & 40.30 & 0.04 \\
Other & 3.20 & 2.20 & 1.96
\end{tabular}

UDL is under detection limit.

other catalysts. Hence, its ability to resist carbon deposition and coking was stronger than the other catalysts. After catalyst usage, the specific surface area decreased and the average pore diameter increased slightly, implying micropores collapsed and carbon deposition occurred during the reaction (Jun et al., 2009). The specific surface area, pore volume and pore diameter of red mud all decreased, which was mainly caused by carbon deposition and bonding. The structural properties of dolomite were relatively stable with little change before and after the reaction.

\section{GC-MS Analysis of the Reactive Phenol}

The formation mechanism of phenolic compounds is complicated, which is attributed to the decomposition of lignin and the coupling effects of cellulose and hemicellulose. 
TABLE 3 | Porous texture of the catalysts before and after reaction.

\begin{tabular}{lccc}
\hline Catalysts & $\begin{array}{c}\text { Specific surface area } \\
\left(\mathbf{m}^{\mathbf{2}} \mathbf{/ g}\right)\end{array}$ & $\begin{array}{c}\text { Pore volume } \\
\left(\mathbf{c m}^{\mathbf{3}} \mathbf{/ g}\right)\end{array}$ & $\begin{array}{c}\text { Mean pore size } \\
\mathbf{( n m})\end{array}$ \\
\hline Raw-HZSM-5 & $364.28 \pm 10.0$ & 0.2541 & 2.24 \\
Used-HZSM-5 & $296.32 \pm 10.0$ & 0.2097 & 3.26 \\
Raw-dolomite & $58.08 \pm 1.5$ & 0.15 & 12.32 \\
Used-dolomite & $58.41 \pm 1.0$ & 0.10 & 11.70 \\
Raw-red mud & $22 \pm 1.0$ & 0.064 & 22.15 \\
Used-red mud & $18 \pm 1.0$ & 0.026 & 14.23 \\
\hline
\end{tabular}

According to the structure of lignin phenylpropane, phenols are generally divided into three categories: phenol, guaiacol and eugenol (Zhao et al., 2011; Shiliang et al., 2014). The hydrogen in the ortho-para-position of the phenolic - $\mathrm{OH}$ is relatively active, which could lead to the production of phenolic resins through the condensation reaction with formaldehyde. The reactivity of the phenols is generally associated with the position and number of substitutions on the benzene ring (Wang et al., 2016; Cui et al., 2017). Hence, phenols in bio-oil were divided into three categories according to the number of active sites (three, two, and one), which were denoted as group A, B and C, respectively.

The content of phenols in bio-oil is displayed in Figure 3. It can be seen that the reactive phenolic content was higher than $0.7 \%$ in the non-catalytic bio-oil. Phenols were mainly produced from the breaking of the connection bond and side chains of lignin. The content of active phenols increased with an increase of the temperature, implying that the demethoxylation of the benzene ring was enhanced. In particular, the content of phenol increased from 2.23 to $4.18 \%$, which mainly resulted from the deoxygenation of guaiacol and eugenol (Shiliang et al., 2014). B-phenols, including phenol-derivatives, were the main active phenols, and they accounted for $37 \%-45 \%$ of the total phenol content. C-phenols mainly consisted of guaiacol-derivatives and accounted for about $35 \%$ of the total active phenol content. Aphenols mainly consisted of phenol, and this group accounted for about $20-27 \%$ of the total phenol content.

As shown in Figure 3, the addition of the HZSM-5 catalyst promoted the content of active phenols, especially A-phenols and B-phenols. This could be attributed to efficient deoxygenation, in which the $\mathrm{C}-\mathrm{O}$ or $\mathrm{C}-\mathrm{C}$ bonds on the guaiacol and syringyl phenols were broken with the aid of the acidic active sites on the catalyst. On the other hand, the porous structure of the catalyst played a significant role in the selective cracking of acids and aldehydes, and the specific structure of the catalyst prevented the entrance of macromolecular aromatic compounds that could decompose the catalyst (Shiyu et al., 2016). However, the content of C-phenols decreased compared with non-catalytic bio-oil. When catalytic pyrolysis was conducted at $550^{\circ} \mathrm{C}$, the total content of A-phenols and B-phenols was $16.14 \%$, which was similar to the content of these phenols produced at $600^{\circ} \mathrm{C}$ (16.34\%), thereby demonstrating that the reaction severity could be reduced through the incorporation of HZSM-5 while still attaining a similar content of phenols.

Red mud was the waste slag produced by aluminum smelting, and it has proven to be an efficient, low-cost catalyst (Yunwu et al., 2019). The total content of active phenols increased from $22.91 \%$ to $24.10 \%$ when the temperature increased from 450 to $600^{\circ} \mathrm{C}$, which implied that the influence of temperature on the generation of active phenols was weakened and the reaction strength was reduced. With the inclusion of red mud, the content of B-phenol and C-phenol remarkably increased by $10.14 \%$ and $47.16 \%$, respectively. B-phenol was the main reactive phenol, and its content accounted for just $<50 \%$ of the total reactive phenol content. Reaction temperature exhibited a less important role in influencing the content of B-phenols. In order to enhance the condensation reaction with aldehydes to produce high valueadded chemicals, the $\mathrm{C}-\mathrm{O}$ and $\mathrm{C}-\mathrm{C}$ bonds of C-phenols, which have only one active site, need to be removed. The content of C-phenol was above $8 \%$ when red mud was incorporated as a catalyst. The content of A-phenols reached the highest value $(5.24 \%)$ at $550^{\circ} \mathrm{C}$, which was relatively low compared to the highest value of the HZSM-5-group. Several of the metal oxides contained in the calcined red mud exhibited synergistic effects resulting in the additional formation of active phenols. The catalytic effect of red mud on active phenols was stronger than that of HSZM-5. Red mud, a kind of alkaline mesoporous catalyst, had a remarkable catalytic effect on the formation of aromatic compounds (Jyoti et al., 2017). However, the related catalytic mechanism stills needs further investigation.

The calcined dolomite was composed of $\mathrm{CaO}$ and $\mathrm{MgO}$, and it contained distorting atomic arrangements and many active sites. The content of A-phenols and B-phenols was promoted while that of $\mathrm{C}$-phenols was inhibited by incorporating dolomite. The impact of dolomite on the content of B-phenols was greater than that of HZSM-5 and red mud. The content of B-phenols accounted for more than $50 \%$ of the total phenolic compounds. When the temperature increased, the content of B-phenols increased and reached up to $16.27 \%$ at $600^{\circ} \mathrm{C}$. Meanwhile, the content of A-phenols, mainly composed of phenol, reached its highest value at this temperature (5.61\%). The content of C-phenols ranged from 4.2 to $5.2 \%$. The increased content of phenols was the result of the activation energy of C-C/C$\mathrm{O}$ bonds being reduced, causing these compounds to break into single-ring aromatics. This was due to the fact that the $\pi$-shaped electron cloud was destroyed, and the stability was reduced when the polycyclic compounds with electronegative constituents were absorbed by the active sites of the catalyst ( $\mathrm{Li}$ and $\mathrm{Wu}, 2009)$. Dolomite with strong alkaline activity sites has been demonstrated to play significant roles not only in enhancing the deoxidation reaction and increasing the phenolic content, but also in reducing the acidity of bio-oil (Shiyu et al., 2016; $\mathrm{Xu}, 2016)$.

In general, the three catalysts exhibited positive effects on increasing the contents of active phenols, especially for Bphenols. The content of A-phenols remarkably increased with the addition of the HZSM-5 catalyst. Due to the catalytic effect of the dolomite catalyst, the formation of B-phenols was enhanced. The content of C-phenols in the bio-oil produced using red mud was significantly greater than that of the C-phenols in the bio-oil produced when using HZSM-5 and dolomite. As for the production of total active phenols, dolomite demonstrated the most significant impact compared with HZSM-5 and red mud. 


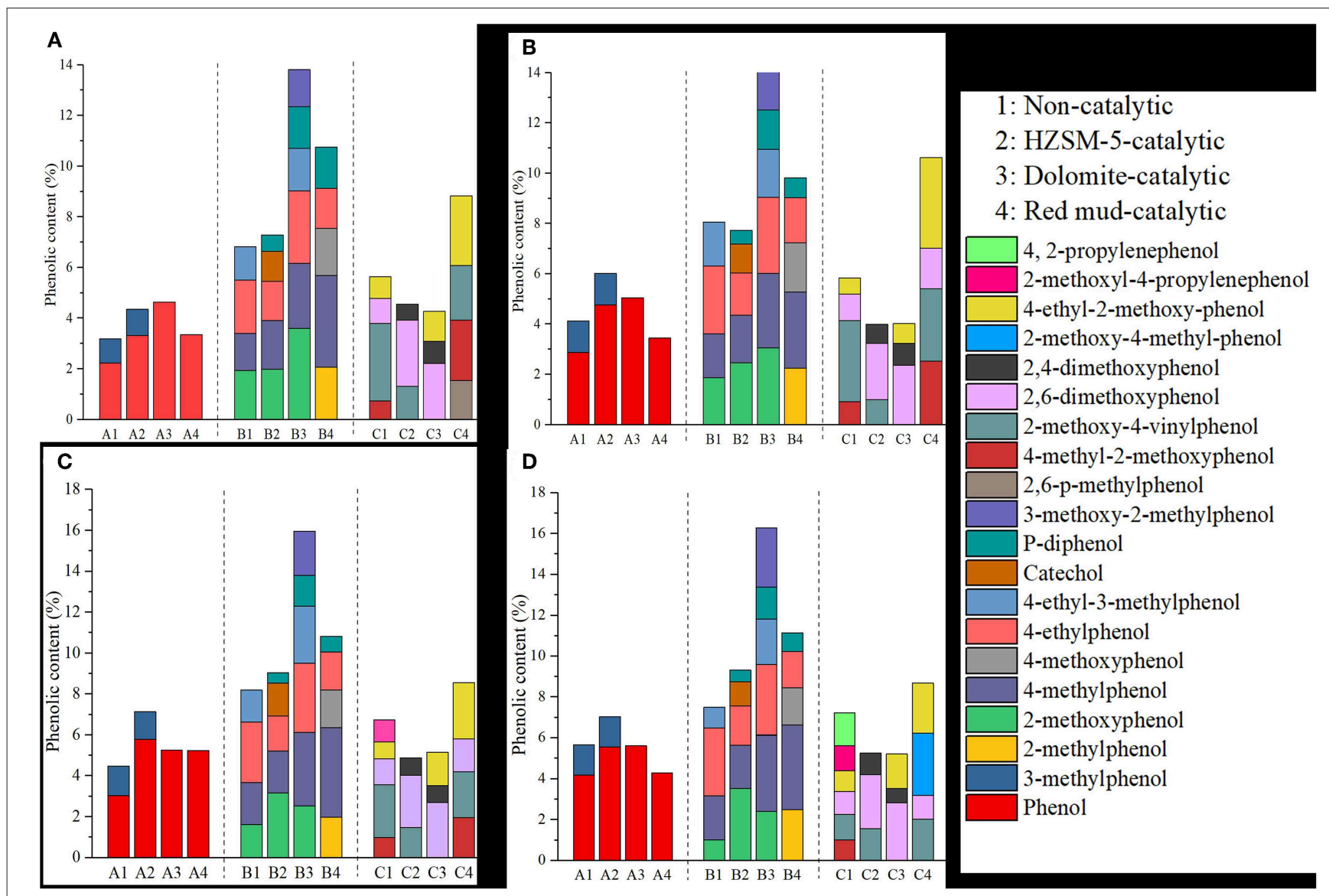

FIGURE 3 | The content of active phenols in bio-oil. (A) $450^{\circ} \mathrm{C}$, (B) $500^{\circ} \mathrm{C}$, (C) $550^{\circ} \mathrm{C}$; (D) $600^{\circ} \mathrm{C}$.

\section{Polycyclic Aromatic Phenols Distribution}

Polycyclic aromatic phenols with high boiling points in bio-oil cannot be detected by GC-MS due to the difficulty of vaporizing these compounds. In order to further investigate the catalytic effect of the three catalysts on the degree of lignin decomposition and monophenol conversion, the content of phenolic - $\mathrm{OH}$ was determined using the FC method. The content of total phenols in bio-oil produced at different temperatures is listed in Table 4. The results indicated that the content of total phenols increased with the addition of the catalyst, demonstrating that the decomposition of lignin was enhanced. Dolomite exhibited the most significant effect on the formation of phenolic compounds, leading to the content of total phenols reaching up to $34.04 \%$ at $600^{\circ} \mathrm{C}$. The catalytic effect of the three catalysts on the total phenolic content was thereby ranked as follows: dolomite $>$ red mud $>$ HZSM-5. This result was also in agreement with the GC-MS results. There were two explanations. The first was that dolomite and red mud are basic catalysts, which are more advantageous for the cracking of etherified phenolic$\mathrm{OH}$ (Cuina et al., 2014). Scholars have found that alkaline additives were beneficial to the thermal cracking of lignin to form monophenolic compounds. Some strong basic solids could effectively promote the deoxygenation of methoxyl (Zhenxi et al., 2019). The second was that mesoporous materials (dolomite
TABLE 4 | The content of total phenols in bio-oil.

\begin{tabular}{lcccc}
\hline Groups & $\mathbf{4 5 \mathbf { 0 } ^ { \circ } \mathbf { C }}$ & $\mathbf{5 0 0}^{\mathbf{}} \mathbf{C}$ & $\mathbf{5 5 0}^{\mathbf{}} \mathbf{C}$ & $\mathbf{6 0 0}^{\mathbf{}} \mathbf{C}$ \\
\hline Control groups & 17.61 & 18.99 & 22.06 & 25.33 \\
HZSM-5 & 19.53 & 21.15 & 25.27 & 25.33 \\
Dolomite & 31.12 & 33.45 & 36.20 & 34.04 \\
Red mud & 26.96 & 28.14 & 29.43 & 29.84 \\
\hline
\end{tabular}

and red mud) have a relatively high specific surface area and porosity, which could provide favorable spatial configuration for macromolecular reactions. But it was more difficult to introduce into the narrow micropore channel (HZSM-5) and impossible to enter the internal active centers to participate in the catalytic reforming reactions for these macromolecular phenolic molecules (Shaoqing et al., 2018).

Hence, it can be concluded that the incorporation of a basic catalyst was more advantageous for the cracking of etherified phenolic - OH. In addition, the content of total phenols increased when the reaction temperature increased from 450 to $600^{\circ} \mathrm{C}$, which implied that a higher temperature played a positive role in the breaking of lignin bonds and the removal of substituents from aromatic rings. 


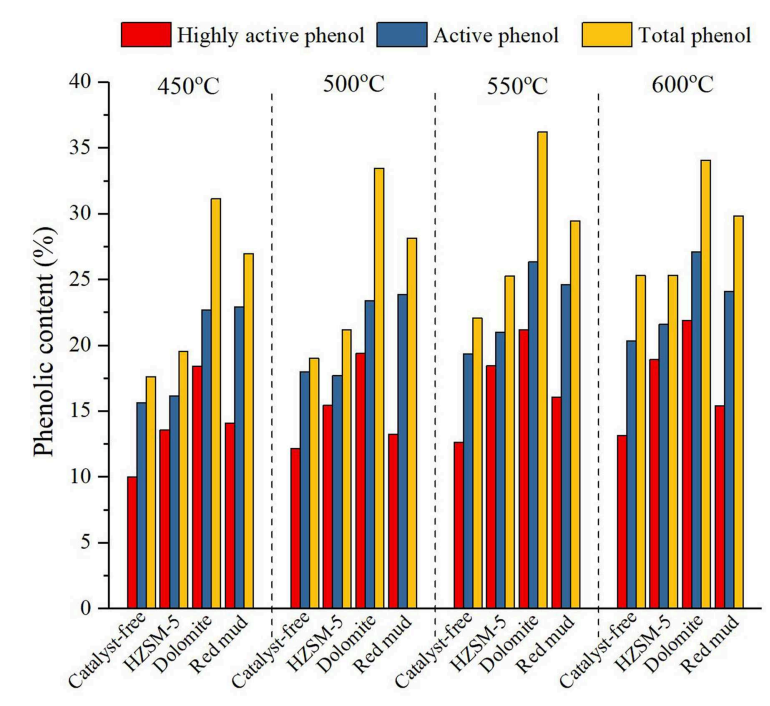

FIGURE 4 | Content of active phenols and total phenols.

\section{Comparison of High Activity Phenols and Total Phenol Content}

When the number of active sites in the active phenols was two or three, phenolic resins could be produced from active phenols and formaldehydes. Hence, the main target product of phenolenriched bio-oil is active phenol, especially highly active phenol (A-phenols and B-phenols with $\geq 2$ active sites), which has the potential to be a promising resource for the production of phenolic resins. In order to comprehensively evaluate the catalytic performance, the content of total phenols, active phenols and highly active phenols was compared. The content of total phenols, active phenols and highly active phenols is displayed in Figure 4.

According to Figure 4, highly active phenol constituted the largest fraction of total phenols, accounting for more than 50\% (except for the red mud-catalytic group at $550^{\circ} \mathrm{C}$ ) of the total phenol content. This result implied that the ortho-position of phenolic hydroxyl in bio-oil had not been completely replaced during pyrolysis of corn stalk. The content of total phenols, active phenols and highly active phenols increased when the temperature increased from 450 to $600^{\circ} \mathrm{C}$, demonstrating that a higher reaction temperature favored lignin cracking. On the other hand, the effect of temperature on the phenolic content was weakened by the synergistic effect of the temperature and the catalyst. In particular, the effect of red mud and dolomite on the content of total phenols and active phenols was dominant. The mesoporous structure and alkali active sites of the two catalysts benefited the adsorption of cracking molecules, the depolymerization of etherified phenolic - $\mathrm{OH}$ and the homolysis reaction into free radicals and fracturing of the aryl ether bond. The catalytic effect of dolomite on the total phenols and highly active phenols was more significant than that of red mud. The homolysis reaction of lignin and the removal of orthopara-substituents of phenolic - $\mathrm{OH}$ were promoted by red mud; however, the formation of highly active phenols was restrained. Regarding the effect of the addition of HZSM-5, the removal of the substituted group in the ortho-para position of phenolic - $\mathrm{OH}$ was enhanced by HZSM-5. Hence, the conversion rate of total phenols to highly active phenols was higher for this catalyst than the other catalysts. At higher temperatures, the catalytic effect of HZSM-5 on the highly active phenols was similar to that of the effect of dolomite.

In general, bio-oil was mainly composed of highly active phenols. Red mud weakened the influence of the reaction temperature, and this catalyst also had an obvious effect on the production of phenols with a single active site rather than highly active phenols. Dolomite and HZSM-5 both played a role in enhancing the production of highly active phenols. With regard to the impact of HZSM-5, the content of phenols with a high boiling point and less active sites increased. Hence, HZSM-5 can be coupled with red mud for catalytic pyrolysis of corn stalk to produce highly active phenols.

\section{CONCLUSION}

In this study, the effects of red mud, dolomite and HZSM-5 on the formation of phenols from corn stalk pyrolysis, including active phenols and highly active phenols, were investigated according to GC-MS and FC analysis. Active phenols were the main components of the bio-oil, amounting to a content $>$ $70 \%$, and these compounds were most notably affected by the incorporation of catalysts. HZSM-5 exhibited the best catalytic effect on the generation of A-phenols, leading to an increase in the content of these phenols of $20.65 \%$. The content of B-phenols and C-phenols increased significantly by 98.66 and $47.16 \%$ by incorporating dolomite and red mud compared with the control, respectively. With regard to the total content of active phenols, the catalytic effect of dolomite (increased by $33.12 \%$ ) was more significant than that of HZSM-5 (increased by $6.02 \%$ ) and red mud (increased by $18.43 \%$ ). The content of total phenols and active phenols was higher than HZSM5 when incorporating red mud as a catalyst. These results provided guidance for the preparation of active phenols for future studies.

\section{DATA AVAILABILITY}

All datasets generated for this study are included in the manuscript/supplementary files.

\section{AUTHOR CONTRIBUTIONS}

LW designed experiments and wrote the manuscript. WY designed the work and revised the important contents. AZ carried out some experiments, sequence data, and developed analysis tools. ZL analyzed experimental results. HC edited and wrote the assistance. YL carried out some experiments.

\section{FUNDING}

This research was supported by the National Natural Science Foundation of China (Nos. 51406109 \& 51536009) and the Shandong Natural Science Foundation of China (Nos. ZR2016YL012, ZR2017MEE004, \& ZR2019MEE036). 


\section{REFERENCES}

Bi, Y. (2010). Study on Straw Resources Evaluation and Utilization in China. Beijing: Chinese Academy of Agricultural Sciences.

Bridgwater, A. (2013). "Chapter 7: Fast pyrolysis of biomass for the production of liquids," in Biomass Combustion Science, Technology and Engineering, 130-171. doi: 10.1533/9780857097439.2.130

Charles, A. M., Akwasi, A. B., Neil, M. G., Isabel, M. L., David, A. L., and Kevin, B. H. (2010). Bio-oil and bio-char production from corn cobs and stover by fast pyrolysis. Biomass Bioenergy 34, 67-74. doi: 10.1016/j.biombioe.200 9.09.012

Cui, Y., Chang, J., and Wang, W. (2017). Synthesis process of bio-oil phenolic resin used for glass-fiber reinforced plastic. J. Forest. Eng. 2, 67-73. doi: 10.13360/j.issn.2096-1359.2017.06.012

Cuina, P., Guangyi, Z., Junrong, Y., and Guangwen, X. (2014). Pyrolysis of lignin for phenols with alkaline additive. Fuel Process. Technol. 124, 212-221. doi: 10.1016/j.fuproc.2014.02.025

Elham, K., Ivo, F. T., Ariel, G., de Resende, E., Christopher, G., Jay, L., et al. (2014). Synergistic co-processing of an acidic hardwood derived pyrolysis biooil with alkaline Red Mud bauxite mining waste as a sacrificial upgrading catalyst. Appl. Catal. B Environ. 145, 187-196. doi: 10.1016/j.apcatb.201 3.02.007

Günay, Ö. (2015). Catalytic pyrolysis of pine wood sawdust to produce biooil:effect of temperature and catalyst additives. J. Wood Chem. Technol. 35, 302-313. doi: 10.1080/02773813.2014.958240

Halil, D. (2016). Pyrolysis of Xanthium strumarium in a fixed bed reactor: effects of boron catalysts and pyrolysis parameters on product yields and character. Energy Sources 38, 1400-1409. doi: 10.1080/15567036.2014.9 47446

Halil, D., Salih, G., and Mehmet, T. (2019). Pyrolysis of black cumin seed: Significance of catalyst and temperature product yields and chromatographic characterization. J. Liquid Chromatogr. Relat. Technol. 42, 331-350. doi: 10.1080/10826076.2019.1593194

Huamei, Y., Koyo, N., Ji, L., Wenyou, Z., Haijun, W. (2018). Effects of HZSM-5 on volatile products obtained from the fast pyrolysis of lignin and model compounds. Fuel Process Technol. 181, 207-214. doi: 10.1016/j.fuproc.2018.09.022

Hyung-Su, J., Kyungbok, B., Mi, S., Sung, M. K., Chul-Ung, K., and Young-Woong, S. (2014). Aromatization of glycerol/alcohol mixtures over zeolite H-ZSM-5. Fuel 134, 439-447 doi: 10.1016/j.fuel.2014.05.086

Ioannidou, O., Zabaniotou, A., Antonakou, E. V., Papazisi, K. M., Lappas, A. A., and Athanassiou, C. (2009). Investigating the potential for energy, fuel, materials and chemicals production from corn residues (cobs and stalks) by non-catalytic and catalytic pyrolysis in two reactor configurations. Renew. Sustainable Energy Rev. 13, 750-762. doi: 10.1016/j.rser.200 8.01 .004

Jewel, A. C., and Sergio, C. C. (2012). Assessing the potential for biofuel production of corn stover pyrolysis using a pressurized batch reactor. Fuel 95, 563-572. doi: 10.1016/j.fuel.2011.12.029

Joshua, K. K., Lavrent, K., and Barry, D. (2015). Phenols from pyrolysis and co-pyrolysis of tobacco biomass components. Chemosphere 138, 259-265. doi: 10.1016/j.chemosphere.201 5.06.003

Jun, P., Ping, C., Hui, L., and Xiaoming, Z. (2009). Catalytic upgrading of biooil by HZSM-5 in sub-and super-critical ethanol. Bioresource Technol. 100, 3415-3418. doi: 10.1016/j.biortech.2009.02.007

Justin, W., Aaron, T., Jared, W., Vidya, S. B., Nida, J., and James, R. K. (2019). Effect of metal oxide redox state in red mud catalysts on ketonization of fast pyrolysis oil derived oxygenates. Appl. Catal. B: Environ. 241, 430-441. doi: 10.1016/j.apcatb.2018.08.061

Jyoti, G., Konstantinos, P., Ivan, V. K., and Elena, Y. K. (2017). Exploring the potential of red mud and beechwood co-processing for the upgrading of fast pyrolysis vapours. J. Analyt. Appl. Pyrol. 128, 35-43. doi: 10.1016/j.jaap.2017.11.002

Karimi, E., Gomez, A., Kycia, S., and Schlaf, M. (2010). Thermal decomposition of acetic and formic acid catalyzed by red mud-implications for the potential use of red mud as a pyrolysis bio-oil upgrading catalyst. Energy Fuels. 24, 2747-2757. doi: 10.1021/ef1000375
Lei, D., Jiaming, Y., Xi, J., and Defu, C. (2018). Transformation and release of potassium during fixed-bed pyrolysis of biomass. J. Energy Inst. 91, 630-637. doi: 10.1016/j.joei.2017.02.009

Li, Y., and Wu, Z. (2009). Effects of catalytic cracking conditions on biomass tar cracking. J Tsinghua Univ. 49, 253-256. doi: 10.16511/j.cnki.qhdxxb.2009.02.005

Lu, Q., Zhang, Y., Tang,. Z., and Zhu, X. F. (2010). Catalytic upgrading of biomass fast pyrolysis vapors with titania and zireonia/ titania based catalyst. Fuel 89, 2096-2103. doi: 10.1016/j.fuel.2010.02.030

Nevenka, R., Nataša, Z. L., Aleksander, R., Mohamad, E. R., Frederic, T. S., Paul, S., et al. (2013). Hardwood lignin pyrolysis in the presence of nano-oxide particles embedded onto natural clinoptilolite. Microporous Mesoporous Mater. 176, 162-167. doi: 10.1016/j.micromeso.201 3.04 .005

Peng, F., Xueyuan, B., Zhihe, L., Weiming, Y., Yongjun, L., Yuchun, Z. (2018). Fast pyrolysis of corn stovers with ceramic ball heat carriers in a novel dual concentric rotary cylinder reactor. Bioresource Technol. 263, 467-474. doi: 10.1016/j.biortech.2018.05.033

Putun, E. (2010). Catalytic pyrolysis of biomass:effects of pyrolysis temperature,sweeping gas flow rate and $\mathrm{MgO}$ catalyst. Energy 35, 2761-2766. doi: 10.1016/j.energy.2010.02.024

Sanna, A., and Andrésen, J. M. (2012). Bio-oil deoxygenation by catalytic pyrolysis: new catalysts for the conversion of biomass into densified and deoxygenated bio-oil. ChemSusChem. 5, 1944-1957. doi: 10.1002/cssc.2012 00245

Shantanu, K., Christopher, M. S., Kevin, A., Zhenglong, L., Ambareesh, M., Dennis, J. M., et al. (2015). A survey of catalysts for aromatics from fast pyrolysis of biomass. Appl Catal B: Environ. 174-175, 85-95. doi: 10.1016/j.apcatb.2015.02.020

Shaoqing, W., Zhihe, L., Xueyuan, B., Weiming, Y., and Peng, F. (2018). Catalytic pyrolysis of lignin with red mud derived hierarchical porous catalyst for alkyl-phenols and hydrocarbons production. J. Analyt. Appl. Pyrol. 136, 8-17. doi: 10.1016/j.jaap.2018.10.024

Shen, D., Liu, G., Zhao, J., Xue, J., Guan, S., Xiao, R., et al. (2015). Thermo-chemical conversion of lignin to aromatic compounds: Effect of lignin source and reaction temperature. J. Analyt. Appl. Pyrol. 112, 56-65. doi: 10.1016/j.jaap.2015.02.022

Shiliang, W., Dekui, S., Jun, H., Huiyan, Z., and Rui, X. (2014). Intensive interaction region during co-pyrolysis of lignin and cellulose: experimental observation and kinetic assessment. BioResources 9, 2259-2273. doi: 10.15376/biores.9.2.225 9-2273

Shiyu, L., Qinglong, X., Bo, Z., Yanling, C., Yuhuan, L., Paul, C., et al. (2016). Fast microwave-assisted catalytic co-pyrolysis of corn stover and scum for bio-oil production with $\mathrm{CaO}$ and HZSM-5 as the catalyst. Bioresource Technol. 204, 164-170. doi: 10.1016/j.biortech.2015.12.085

Wang, W., Geng, J., Li, L., and Chang, J. (2016). Catalytic properties of fast pyrolysis char loaded with $\mathrm{Cu}-\mathrm{Zn}$ on alkali lignin pyrolysis for monophenols. Chem. J. Chin. Univ. 37, 736-744. doi: 10.7503/cjcu201 50681

Wen, J., Anuj,. K., and Stergios, A. (2018). Liquefaction of lignocellulosic materials and its applications in wood adhesives-a review. Indus. Crops Product. 124, 325-342. doi: 10.1016/j.indcrop.2018.07.053

Wen-Liang, W., Xue-Yong, R., Lu-Fei, L., Jian-Min, C., Li-Ping, C., and Jing, G. (2015). Catalytic effect of metal chlorides on analytical pyrolysis of alkali lignin. Fuel Process. Technol. 134, 345-351. doi: 10.1016/j.fuproc.201 5.02 .015

Xu, M. (2016). Research of the Physical and Chemical Properties and Composition Distribution of Bio-Oil of Catalytic Pyrolysis Corn Stover. Shandong: Shandong University of Technology.

Yi, L., Liu, H., Xiao, K., Wang, G., Zhang Q., Hu, H., et al. (2019). In situ upgrading of bio-oil via $\mathrm{CaO}$ catalyst derived from organic precursors. Proc. Combust. Instit. 37, 3119-3126. doi: 10.1016/j.proci.2018.06.078

Yu, N., Cai, Y., Li, X., Fan, Y., Yin, H., and Zhang, R. (2014). Catalytic pyrolysis of rape straw for upgraded bio-oil production using HZSM-5 zeolite. Transac. Chin. Soc. Agricul. Eng. 30, 264-271. doi: 10.3969/j.issn.1002-6819.2014.15.034

Yunwu, Z., Lei, T., Yuanbo, H., Can, L., Zhen, W., and Zhifeng, Z. (2019). Improving aromatic hydrocarbon content from catalytic pyrolysis upgrading 
of biomass on a CaO/HZSM-5dual-catalyst. J. Analyt. Appl. Pyrol. 140, 355-366. doi: 10.1016/j.jaap.2019.04.014

Zhao, J. N., Zhang, G. L., and Yang, D. L. (2011). Estimation of carbon emission from burning of grain crop residues in China. J Agro-Environ. Sci. 30, 812-816.

Zhenxi, Z., Kai, L., Shanwei, M., Minshu, C., Qiang, L., and Yong-ping, Y. (2019). Fast pyrolysis of biomass catalyzed by magnetic solid base catalyst in a hydrogen atmosphere for selective production of phenol. Indus. Crops Products. 137, 495-500. doi: 10.1016/j.indcrop.2019.05.066

Zhou, J., Liu, Y., Luo, Z., and Cen, K. (2005). Effects of solid acid and alkali catalysts on catalytic cracking of biomass tar. J Zhejiang Univ. 39, 1047-1051. doi: 10.3785/j.issn.1008-973X.2005.07.027
Conflict of Interest Statement: The authors declare that the research was conducted in the absence of any commercial or financial relationships that could be construed as a potential conflict of interest.

Copyright $\odot 2019$ Wang, Yi, Zhang, Li, Cai and Li. This is an open-access article distributed under the terms of the Creative Commons Attribution License (CC BY). The use, distribution or reproduction in other forums is permitted, provided the original author(s) and the copyright owner(s) are credited and that the original publication in this journal is cited, in accordance with accepted academic practice. No use, distribution or reproduction is permitted which does not comply with these terms. 